\title{
Eu sou o samba: sobre lugares, pessoas e pertencimento'
}

\author{
Renata de Sá Gonçalves \\ Doutora em Antropologia Cultural (Universidade Federal do Rio de Janeiro) \\ Professora da Universidade Federal Fluminense (UFF) \\ Niterói, Brasil \\ sarenata2005@yahoo.com.br
}

\begin{abstract}
Resumo Este artigo está centrado na reflexão sobre determinados "lugares" associados ao samba da cidade do Rio de Janeiro, tendo em conta aqueles considerados emblemáticos na literatura especializada sobre o tema. O objetivo é compreender as relações entre o samba, as pessoas e os lugares, indicando os diversos arranjos territoriais, morais e afetivos que os engendram, como também a presentificação desses lugares nos movimentos sociais, nas manifestações festivas e nos processos de patrimonialização.
\end{abstract}

Palavras-chave: samba, lugar, pertencimento, Rio de Janeiro, patrimônio cultural.

\section{Introdução}

$\mathrm{N}$ os centros e nas áreas periféricas de muitas cidades brasileiras, um número expressivo de pessoas, com interesses e projetos de vida os mais variados, integram grupos musicais, participam de rodas, divertem-se em bares, clubes, quadras e terreiros e apreciam essa expressão cultural que agrega música, dança, performance e encontros festivos. A mídia televisiva e o relativo sucesso fonográfico atestam a expressividade dessa manifestação.

Este artigo propõe uma discussão sobre o samba no Rio de Janeiro, com foco nos "lugares" que se configuraram como emblemáticos e apontados pela literatura especializada e interessada pelas origens do samba e a presentificação desses lugares e de seus sentidos, nos movimentos sociais, nas manifestações festivas, nas reivindicações de direitos e por seu registro como patrimônio cultural (Mota, 2012; Oliveira et. al., 2012; Guimarães, 2012).

Muito já se falou sobre as origens do samba, a evolução do gênero musical, sua circulação, difusão e mediação social. A literatura que comenta e analisa o samba no Rio de Janeiro é muito diversificada e vem sendo produzida por músicos, poetas, cronistas, folcloristas e tem ganhado interesse do campo das Ciências Humanas (Gonçalves, 2003). Ressaltam-se nos escritos, de forma geral, referências à "Pequena África", à casa da tia Ciata, à Cidade Nova, aos terreiros e, mais recentemente, ao Sambódromo e às escolas de samba - lugares onde se produziu e se produz, onde se canta, dança, vive e se experimenta o samba. A literatura também enfatiza os trânsitos entre migrantes, destacando especialmente algumas relações com os baianos e, em alguns casos, alargando ainda mais o horizonte, com uma ideia estendida de África.

1. Agradeço à Faperj pelo apoio ao projeto de pesquisa "Transmissão do Conhecimento entre tradições populares. Dinâmicas de reinvenção da cultura", que coordeno no âmbito do Núcleo de Artes, Ritos e Sociabilidades Urbanas (Narua) da Universidade Federal Fluminense. 
Além da produção bibliográfica sobre o tema, que em si mesma revela diferentes interesses e propósitos, também levarei em conta neste artigo o texto produzido para o dossiê que embasou o processo de registro das "matrizes do samba: partido alto, samba de terreiro e samba enredo" como patrimônio imaterial, realizado pelo Instituto do Patrimônio Histórico e Artístico Nacional (Iphan). Naquele contexto, em 2005, uma equipe ${ }^{2}$ foi coordenada pelo Centro Cultural Cartola,${ }^{3}$ com o apoio e financiamento do Iphan. O texto produzido foi resultado do trabalho desse grupo, motivado a pesquisar, reunir material e analisar "os variados estilos de samba no Rio de Janeiro, que se originaram nas reuniões musicais em casa de Tia Ciata, no Estácio, nas escolas de samba, nos blocos, nos morros, nas ruas, nos quintais" (CCC/Iphan, 2007, p. 9). Seguindo esse movimento, o Iphan registrou no ano de 2007 as "matrizes do samba no Rio de Janeiro" como integrante do patrimônio cultural brasileiro, aferindo um estatuto novo e diferenciado a essa expressão cultural.

Com base em tais perspectivas, proponho refletir sobre alguns dos "lugares" emblemáticos do samba evocados com certa regularidade na literatura sobre o tema, buscando compreender como tais lugares foram criativamente narrados e experimentados de modo a conectar pessoas e relacionar categorias de pensamento, como as de tempo, espaço, poder e patrimônio. Pretendo, assim, indicar o potencial analítico da relação indissociável entre lugares e pessoas no âmbito da proposta de uma antropologia do lugar (Rodman, 2003; Basso, 1996; Casey, 1996).

\section{O samba e os lugares - por uma antropologia do lugar}

Se a literatura sobre o gênero musical apresenta associações entre o samba e determinados lugares e pessoas que se reúnem, fazem, cantam e dançam o samba, é preciso enfrentar mais diretamente o desafio de responder o que tais conexões podem revelar, contribuindo para uma discussão mais ampla no âmbito da antropologia do lugar. Mas, antes de qualquer coi- sa, é preciso compreender como o "lugar" tem sido abordado no campo de estudos da Antropologia.

É antigo o interesse teórico e metodológico acerca do espaço como categoria privilegiada do entendimento humano. Trajano Filho (2010) revela a amplitude do campo semântico de conceitos como espaço, lugar, paisagem e território e exemplifica o seu uso ao longo de vertentes da teoria antropológica. No início do século XX, Franz Boas (1934), importante autor da antropologia norte-americana, indicava que um meio privilegiado de acesso aos povos indígenas se encontrava nos nomes dados por eles ao ambiente físico. Na França, os sociólogos Emile Durkheim e Marcel Mauss (1981) 4 investigaram o caráter eminentemente social das formas de classificação em que a noção de território se dá por meio do espaço, entendido como categoria fundamental do entendimento. Lévi-Strauss (1975), em sua antropologia estrutural, procurava correlacionar os arranjos espaciais das aldeias a modelos nativos sobre a estrutura social.

Se tais tópicos estiveram no centro da tradição antropológica da primeira metade do século XX, em meados dos anos 1960 imputava-se certo esgotamento a esse campo de estudos. Na década de 1980, houve um interesse renovado pelos estudos dos territórios, que foram retomados sob a égide de uma suposta nova época - a da globalização, com suas fronteiras móveis e fluidas.

Na crítica feita por Trajano Filho (2010), os estudos da globalização e das sociedades pós-coloniais apresentam um jargão próprio para lidar com um mundo compreendido como cada vez mais igual e hiperterritorializado, e, paralelamente, cada vez mais local, pela ressurgência da etnicidade e da ideologia da localidade. Entretanto, a compreensão de um "novo mundo" globalizado tem sido naturalizada e simplificada, como alerta o antropólogo. A visão sobre o processo mundial de globalização, como uma novidade que demanda termos inéditos para expressá-la, nos fez esquecer a contribuição passada da Antropologia sobre a dimensão territorial da vida social.

O ponto que quero destacar refere-se, portanto, à perspectiva essencial de que os lugares não são dados a priori em um mundo exterior ao sujeito, e sim construídos em meio às interações sociais. A espacia-

\footnotetext{
2. A equipe técnica foi coordenada pela neta do conhecido sambista Cartola, Nilcemar Nogueira, atual coordenadora de projetos do Centro Cultural Cartola, responsável pelos projetos de arte educação e coordenadora de pesquisa do programa samba patrimônio imaterial.

3. Organização sem fins lucrativos, fundada em janeiro de 2011 na Mangueira, Rio de Janeiro. Empreende projetos sociais associados à música, dança e manifestações culturais.

4. Durkheim e Mauss, em artigo intitulado "Algumas formas primitivas de classificação", cuja primeira edição é de 1903, inferem que, na tribo "Wotjoballuk", "a divisão dos espaços acha-se tão estreitamente ligada àquilo que há de mais essencial na sua organização social" que [...] "é uma regra geral que os grupos secundários da tribo, das fratrias, dos clãs e subclãs se disponham no espaço conforme suas relações de parentesco e as semelhanças ou as diferenças que suas funções sociais oferecem. Porque as duas fratrias têm personalidades distintas, porque cada uma exerce uma função diferente na vida da tribo, elas se opõem espacialmente: uma se estabelece de um lado, a outra, do outro; uma é orientada num sentido, a outra no sentido oposto" (Durkheim; Mauss, 1981, p. 438-439).
} 
lidade, portanto, não deve ser restringida à territorialidade física. Ao avançar nessa discussão, a antropóloga Margaret Rodman (2003) propõe abordar o lugar não como um dado etnográfico essencializado pelo próprio pesquisador, e sim a partir das múltiplas possibilidades de se experimentar o lugar. Essa compreensão pretende ultrapassar a análise de contextos localizados em um espaço definitivo, para dar vazão a experiências dos agentes com/sobre o lugar. Desse modo, a autora ressalta a importância de indicar as relações de poder subjacentes às experiências dos lugares, aspecto negligenciado em muitos estudos antropológicos. Ao fazer um bom aproveitamento da discussão do "lugar" na geografia, a autora propõe explorar o que chama de "multivocalidade" e "multifocalidade" (2003), ou seja, compreender os lugares como espaços sociais de múltiplas experiências, povoado por vozes e perspectivas que expressam arranjos sociais mais ou menos hegemônicos.

Os sentidos do lugar vão, portanto, além dos sentidos discursivos hegemônicos e devem indicar múltiplas perspectivas em movimento. Keith Basso (1996) destaca, no prefácio de seu livro Wisdom sits in places, que as vinculações das pessoas aos lugares são necessariamente interdependentes. Afinal, os lugares são tão parte de nós, como nós somos parte deles (p. xiv). A epígrafe do primeiro capítulo de seu livro expressa bem sua posição sobre a natureza imbricada entre as pessoas e os lugares, reciprocamente constituídos: "Lugar é o primeiro de todos os seres, uma vez que tudo o que existe está em um lugar e não pode existir sem um lugar". 5 A experiência de sentir os lugares é sempre dinâmica e não pode ser conhecida previamente. Os lugares animam ou interanimam ideias, sentimentos e pessoas.

Tais perspectivas parecem-nos estimulantes para compreender a recorrência da associação do samba aos lugares e às pessoas.

\section{Na Casa da tia Ciata e no Estácio}

Um ponto importante a ser destacado na literatura sobre o samba trata dos primeiros lugares onde ele passa a ser cantado e tocado. O etnomusicólogo Carlos Sandroni (2001) explora a categorização nativa do samba no início do século XX no Rio de Janeiro. Um tipo de samba seria aquele que se faz, se toca e se dança nas casas de tia Ciata e outras 'tias' baianas, com Donga, João da Baiana, Sinhô, Caninha, Pixinguinha. As diferenças não são bem especificadas na literatura sobre o samba de então, produzida principalmente por nativos do mundo do samba. A diferença é reconhecida "de ouvido". Aqui, portanto, os sentidos dados à casa de Ciata e às pessoas que a frequentam conectam-se com as próprias diferenças rítmicas e de estilo do samba.

Sandroni (2001) sintetiza que o samba pode ser definido em três momentos: o samba folclórico, o samba amaxixado e, de 1928 em diante, o samba em sua acepção mais moderna, com o advento do paradigma do Estácio, com Ismael Silva, Nilton Bastos, Bide, Brancura e outros. A problemática do samba como gênero leva em conta um conjunto de características, que vão desde caracteres formais - natureza rítmica, letra, melodia, estilo - até temas, comportamentos e usos sociais. Portanto, o status unificador do samba deve ser pensado em termos de uma diversidade social e estética que configurou nomes e lugares distintos.

A interpretação proposta pelo autor elabora, por meio do estudo musicológico, uma divisão que já vinha sendo posta pelos músicos e também pelos cronistas do samba, "pelos ouvidos". Além do samba nas casas das tias e nas rodas, há outro sentido do samba, aquele que começa a ser designado como gênero de música popular a partir dos anos 1930 . O cronista Vagalume, ${ }^{6}$ no livro $A$ roda de samba, cuja primeira edição data de 1933, fala do "estilo antigo" como representante da "tradição" e do "estilo novo" representando a "comercialização". Vagalume separa os originários da roda de samba, "boca da gente de roda", e os que são estrangeiros a ela, como Ary Barroso e Francisco Alves. Este último foi considerado o grande astro do rádio e do disco no Brasil, tendo investido na compra dos sambas. Orestes Barbosa, ${ }^{7}$ em Samba, livro também datado de 1933, dedica especial atenção, entre os compositores do velho estilo, a Sinhô, considerado o maior entre os "mortos do samba".

As narrativas dos cronistas estão atreladas a uma rica vivência cotidiana com as pessoas e os lugares por onde passavam. Em virtude do próprio caráter do texto jornalístico, potencializado pela ênfase na "crônica-reportagem", estilo que se destacou no começo do século XX, a tônica dos escritos dos cronistas estava em suas experiências pessoais, nos relatos de suas descobertas e andanças pela cidade do Rio de Janeiro. Os cronistas eram convidados pelos grupos car-

\footnotetext{
5. Do inglês: "Place is the first of all beings, since everything that exists is in a place and cannot exist without a place". Archytas, como citado por Simplicius (Basso, 1996, p. 3). Comentários sobre as categorias de Aristóteles.

6. O cronista Francisco Guimarães, falecido em 1946, trabalhou em diversos jornais cariocas durante cerca de cinquenta anos. Foi pioneiro ao criar uma coluna sobre notícias carnavalescas no Jornal do Brasil, onde assinava com o pseudônimo de Vagalume.

7. Orestes Barbosa (1893-1966). Importante cronista da cidade do Rio de Janeiro na década de 1920, escreveu nas páginas de A Manhã, A Notícia e Crítica.
} 
navalescos a participar de suas festividades. Narravam desde os ensaios, as festas, as atividades realizadas no decorrer do ano até os desfiles e a apuração dos votos nos concursos, muitas vezes promovidos pela própria imprensa. Foram ativos participantes e mediadores no processo de legitimação das associações carnavalescas. Formularam uma noção de cultura popular urbana competitiva, negociada cotidianamente, experimentada pelos diversos atores sociais nas constantes disputas na cidade do Rio de Janeiro (Gonçalves, 2003).

Ao acompanhar a argumentação de jornalistas e cronistas das primeiras décadas do século XX, nota-se que a palavra samba designou dois gêneros musicais, cujos lugares de execução se diferenciavam. Podia ser tocado em salas de visitas ou nas rodas de samba das tias baianas e por músicos treinados ou não. Ao produzir essa ambiência, a literatura destaca essa região onde moravam as tias e muitos migrantes negros e ex-escravos na cidade do Rio, território que ficou conhecido posteriormente como "Pequena África", principalmente em razão do livro Tia Ciata e a pequena África, do cineasta Roberto Moura, publicado em 1983. Essa região da cidade, que foi divulgada por Moura em seu livro, corresponde, nas primeiras décadas do século XX, à área situada entre o Cais do Porto e a Cidade Nova, em torno da Praça Onze (Moura, 1995).

A antropóloga Roberta Guimarães (2012) faz uma leitura crítica da abordagem narrativa de Moura, que reúne e organiza dramaticamente um conjunto específico de genealogias, mitos de origem, ancestrais sagrados e deuses, parte de um mundo advindo de uma "diáspora baiana" e africana, criando assim imagens do "patrimônio negro". Segundo a autora, esse patrimônio é atualizado principalmente na década de 1980, por meio do que chamou de presentificação desse "mito da Pequena África" (p. 305). Com essas imagens, o governo estadual produziu em alguns desses lugares emblemáticos, como no entorno da extinta Praça Onze, símbolos referentes à cultura negra. Em 1984, foram inaugurados o sambódromo e o Terreirão do Samba, espaços associados à musicalidade negra. Em 1986, foi inaugurado o monumento a Zumbi dos Palmares e, na zona portuária, o Centro Cultural José Bonifácio. Entre 1984 e 1987 foi realizado o processo de tombamento estadual da Pedra do Sal (Guimarães, 2012, p. 308).

Oliveira e outros autores (2012) relatam o "Movimento Samba na Fonte", formado por compositores que desde 2007 se reúnem semanalmente na Pedra do Sal para cantar composições de suas próprias autorias. Segundo os autores, com a presença do grupo que faz samba na rua, "o lugar toma nova funcionalidade que não lhe é totalmente estranha, considerando seu estatuto de práticas culturais negras do passado" (p. 195).

São lugares, portanto, onde as imagens e os sentidos de resistência e de reação impressas na história do próprio samba são difundidos por meio da associação a um legado negro. O sociólogo Diego Alves (2006) atenta para o fato de que, de um modo geral, a literatura sobre o tema atribui um caráter homogêneo à vida social desses imigrantes baianos. Pouco se discutiu sobre a dimensão conflitiva "interna" desse grupamento. Para o autor, o que se percebe é o desempenho de uma espécie de liderança comunitária exercida pelos imigrantes baianos entre os segmentos populares do Rio de Janeiro no início do século XX. Liderança que, supõe-se, foi fundamental para a criação de uma identidade social baiana durante o período da belle époque carioca. Alves argumenta que a formalização das imagens e dos significados de Bahia, na cidade do Rio de Janeiro, se dá em consonância com o desenvolvimento de determinadas esferas lúdicas e de diversão populares da cidade, que, desde aí, já ganhavam contornos de música e festa popular nacionais, por excelência: o samba e o carnaval (p. 117).

É nesse contexto de encontros musicais e festivos que, segundo Velloso (1990), as mulheres negras baianas formavam redes de sociabilidades, agregavam sua energia participativa na criação de suas próprias organizações, como ranchos, cordões, terreiros, espaços que propiciam a consolidação de redes de relações, reunindo elementos dispersos pela experiência da escravidão. Velloso chama ainda a atenção para o fato de que essa sociabilidade, baseada em papéis liminares, tem sido praticamente ignorada pela nossa historiografia (p. 210).

Nas narrativas sobre a "Pequena África" há a referência direta à participação central dos baianos, representados exemplarmente por alguns homens que ganham destaque, como João Alabá ou Hilário Jovino, e por algumas mulheres, atuantes não apenas nas reuniões dos candomblés da cidade. Eram as chamadas "tias baianas", que figuravam como mães de santo, mas também nas festas populares nas ruas, articulando pontos de encontro para comemorações e festividades diversas.

Como um dos primeiros sinais públicos da importância dos baianos na vida do Rio, tia Bebiana impõe sua festa da lapinha no Largo de São Domingos, que se torna um lugar de convergência dos desfiles dos pastoris e ranchos existentes pela cidade na época do natal ainda na década de 1880. (CCC/Iphan, 2007, p. 17)

A "cultura das ruas" é uma das articulações evidenciadas, em que "o carnaval, o candomblé, o samba, a festa da Penha, os presídios, os mafuás, as praças ou as ruas da cidade são lugares que condensam essa multiplicidade do urbano" (Velloso, 2004, p. 22).

A atuação expressiva musical desempenhava uma experiência diferenciada com o lugar, diferentemente da prática mais habitual na cidade do Rio de Janei- 
ro, que passa a se configurar, principalmente com as reformas urbanas do começo do século, de forma a separar o "centro" dos subúrbios, em um nível mais amplo, e a "casa" e a "rua", em outro nível. A rivalidade estava presente entre os grupos recreativos e carnavalescos que disputavam seu "lugar" nas ruas. Demarcá-los significava ocupar lugares sociais nesse sistema social que se constituía em meio a grandes assimetrias sociais. Nomes de cordões, como "Pés Espalhados" e "Rompe e Rasga", indicavam como os espaços iam sendo requeridos e marcados com os próprios pés e mãos, além de o serem também nas comissões de frente que inauguravam os caminhos para o rancho passar, nas músicas que "abriam alas", nos percursos que teciam longos e difíceis desenhos na cidade (Velloso, 2004).

Essas narrativas se referem, sobretudo, à virada do século XIX para o século XX. Muitos de seus aspectos são retomados, por meio da relação interdependente entre as pessoas e os lugares. Nos textos "escolas de samba", originalmente publicados em 1956 e 1957, Edison Carneiro (2008) leva em conta a integração popular no espaço da cidade, revelando a centralidade do ponto do subúrbio ou do morro. Essa manifestação, nas palavras do folclorista, espalha-se em vários subúrbios, em morros e na área metropolitana do então Distrito Federal. Destaca ainda sua expansão pelo país, afirmando que "a escola vai ganhando, paulatinamente, outras capitais, tanto do Norte como do Sul" (Carneiro, 1982, p. 87).

A visão ambivalente das escolas de samba, que o folclorista defendeu, buscou dimensionar sua continuidade entre os folguedos populares, mas destacou paralelamente singularidades e críticas ao que chamou de seu "processo evolutivo". Sobre as disputas, Carneiro (2008, p. 81) menciona "o encontro das escolas na Praça Onze onde resolviam suas divergências, a faca, a pau, a pernada, a pandeiro de tarraxa”. Essas disputas seriam acentuadas pela concessão de prêmios por juízes venais e amenizadas com a criação da Associação em 1952, tradição disciplinada pelos regulamentos.

\section{Os lugares e os processos de patrimonialização}

Toda essa literatura sobre a primeira metade do século XX não está distante dos discursos e das narrativas produzidos atualmente no processo de patri- monialização do ano de 2007, que abrigou o registro e a salvaguarda das matrizes do samba.

O texto do dossiê do Centro Cultural Cartola/ Iphan (2007), escrito por vários autores, ${ }^{8}$ inclui alguns consultores convidados para a redação de conteúdos especificados, já nossos conhecidos por sua produção sobre o tema, como o jornalista Sergio Cabral, o compositor e escritor Nei Lopes, o etnomusicólogo Carlos Sandroni e o cineasta Roberto Moura, entre outros. Vemos reforçadas as narrativas que estabelecem determinadas demarcações precisas, como a casa de tia Ciata, a Pedra do Sal, o Morro da Conceição, lugares associados aos ex-escravos, aos migrantes baianos e às populações negras vindas de várias partes da África.

Em diversos trechos selecionados do dossiê, há a referência direta às tias baianas que figuravam como mães de santo, mas também à organização das festas populares nas ruas, promovendo populares comemorações e marcos festivos diversos. Seguem trechos do dossiê nos quais se enfatizam tais relações:

Tendo como marco a localidade denominada Pedra do Sal, no morro da Conceição na zona portuária do Rio de Janeiro, nas primeiras décadas do século XX, o samba carioca se apresenta desde sua origem como um elemento de expressão da identidade cultural da população negra.

$[\ldots]$

Essa população marginalizada se reuniu na região conhecida como Cidade Nova e em torno da casa da baiana Tia Ciata, formou um poderoso núcleo de resistência cultural, cuja produção vigorosa começou a furar o bloqueio social, econômico e geográfico. Em 1917, pela primeira vez, um selo de disco de 78 r.p.m. trouxe, no campo reservado à descrição do gênero musical, a palavra samba. (CCC/Iphan, 2007, p. 13)

É especialmente destacada a presença do candomblé e das filhas de santo na configuração desse espaço da cidade. No texto, o caminho da zona portuária para a Cidade Nova ganha destaque. Nesse caminho, instalou-se o candomblé da casa de João Alabá, de Omulu, na rua Barão de São Félix,

instituição popular que se constituiu como numa garantia para o negro no Rio de Janeiro, vitalizando-o para resistir e sustentar seus novos caminhos na cidade e no país. Suas filhas-de-santo marcaram época como as rainhas negras do Rio Antigo: tia Amália, Amália Silvana de Araújo, mãe do violonista e com-

\footnotetext{
8. A pesquisa para o dossiê foi empreendida por Helena Theodoro, Aloy Jupiara e Rachel Valença e por consultores convidados: Nei Lopes (Da tradição africana), Roberto Moura (Notas para uma história afro-carioca), Sérgio Cabral (Deixa Falar, o samba e a escola), Carlos Sandroni (A música), Felipe Trotta (A música); João Batista Vargens (A poesia), Marília de Andrade (A dança), Carlos Monte, Haroldo Costa, Janaína Reis e Lygia Santos, além de assistentes de pesquisa.
} 
positor Donga; Perciliana Maria Constança, ou melhor, tia Perciliana do Santo Amaro; tia Mônica e sua prodigiosa filha, Carmem Teixeira da Conceição, a Carmem do Xibuca, a filha de Alabá que vive, sábia e soberana, até a década de 1980 com seus mais de 110 anos; a tia Bebiana dos ranchos; tia Gracinha, que foi mulher do grande Assumano Mina do Brasil, sacerdote islâmico; tia Sadata do rancho Rei de Ouro; e a grande tia Ciata 1854-1924), Hilária Batista de Almeida, mãe-pequena do candomblé de João Alabá, lideranças fundamentais para uma verdadeira revolução que se travaria no meio negro naquela zona depois da libertação. (CCC/Iphan, 2007)

Diante da forte relação estabelecida entre pessoas, os lugares do samba na cidade do Rio se expandem, promovendo a conexão com outros tempos e espaços. Assim, a relação entre tempo e espaço se faz na experiência com o lugar, revelando muitos de seus meios e níveis (Casey, 1996).

\section{A expansão dos lugares}

Ao descrever a atuação contemporânea do samba, há, ainda no texto do dossiê, a apresentação de outros importantes vínculos com lugares da cidade: as quadras, o sambódromo, as escolas que desfilam em Campinho, subúrbio da cidade. Há ainda a presença do samba nos clubes, nos bares, nos trens.

Se na quadra da escola o samba-enredo hoje domina, no bar Candongueiro, em Pendotiba (Niterói), o partido-alto impera. Não há sambista que não se sinta em casa no Candongueiro. Para o Samba do Trabalhador, no Clube Renascença (no Andaraí), também convergem velhos e novos adeptos do samba de linha mais tradicional. A renovação do bairro da Lapa, com a abertura de bares e centros culturais que dá espaço e destaque aos sambistas tradicionais, criou nos últimos anos um circuito alternativo para apresentação de sambas de terreiro e de partido-alto. A geografia do samba no Rio de Janeiro se transforma a todo momento, com ganhos de um lado e perdas de outro. Nas perdas, a tensão, muitas vezes, está presente. E "perda" não significa necessariamente o fechamento físico de espaços tradicionais, mas o aumento da con- corrência com a entrada na cena de outros gêneros de música, como o funk. (CCC/Iphan, 2007, p. 89)

Desde o seu período de formação, acompanhando as redes sociais, os deslocamentos internos, a expansão do rádio e da indústria fonográfica, o samba, como uma expressão musical, performática, dançada, desenhava-se no espaço da cidade, por meio das rodas de samba e das escolas, espraiando-se ainda por diferentes cidades do país e servindo de modelo para outras.

Sobre as escolas de samba de São Luís do Maranhão, Araújo (2001) investiga a criação, o desenvolvimento, a decadência e a resistência das escolas de samba de São Luís do Maranhão. Esses grupos, existentes desde a década de 1930, após considerável período de ascensão abrilhantando o carnaval local, começaram em 1970 a ser criticados como cópias das escolas cariocas, considerados inautênticos e relegados a um segundo plano pelas políticas culturais locais.

É importante destacar, paralelamente, pesquisas mais recentes que detalham a relação entre as escolas de samba ${ }^{9}$ e o sentimento de pertencimento ao bairro. Barbieri (2010), em seu estudo sobre a pequena escola Acadêmicos do Dendê, ${ }^{10}$ identifica que muitas das pessoas que compõem essa escola de samba participam também das duas outras escolas da Ilha do Governador. Esse fato é recorrente. Ao falarem sobre suas adesões, recorrem a uma identidade englobante. Explica o autor, que, entretanto, quando confrontados por membros ou torcedores de escolas maiores de fora da Ilha, esses mesmos componentes recorrem à "identidade primária" na maior parte dos casos e tornam-se "Ilha" ou "União" (Barbieri, 2010, p. 54).

Poubel (2012), ao estudar a escola de samba Vila Isabel, ressalta que a falta de limites bem definidos do que é a comunidade de Vila Isabel faz com que todos os adeptos sejam parte dela. A "comunidade" engloba a todos que se sentirem participantes. As pessoas têm na escola o estabelecimento de discursos e práticas em comum e pertencer a uma mesma escola de samba influencia e dá significados compartilhados amplamente. Esse sentimento de pertencimento, como explica a autora, é utilizado pela diretoria da escola de samba para mobilizar seus componentes em torno de uma causa comum: as alas da comunidade.

Ao estudar escolas da cidade de São Paulo, Dozena (2009) identifica que ser da Unidos do Peruche,

9. Além dos contextos de músicos de samba que circulam por todo o país, levando em seus sambas os lugares do Rio, as escolas de samba expandiram-se no século XX entre várias cidades brasileiras. Em São Paulo (Simson, 2007; Blass, 2007), São Luís (Araújo, 2001), Manaus (Sales, 2008), Recife (Menezes, 2010), Porto Alegre (Guterres, 1996; Prass, 1998), Belém e Teresina (Araújo, 2008), Vitória (Monteiro; 2010) e Florianópolis (Silva, 2005).

10. A escola de samba Acadêmicos do Dendê foi fundada oficialmente em 1992, originária do bloco Unidos do Dendê e Unidos da Cova da Onça, ambos fundados em 1962. Pela sua localização, a agremiação caracterizou-se por forte aproximação com os moradores do Morro do Dendê. O morro fica entre a região próxima da quadra da União da Ilha, localizada no bairro do Cacuia, e a antiga quadra do Boi da Ilha do Governador, localizada na Freguesia (Barbieri, 2010, p. 65-66). 
da Pérola Negra, da Nenê da Vila Matilde ou da Vai-Vai expressa, para a maioria das pessoas, um forte sentimento de pertencimento à escola de samba e ao lugar; sentimento de "donos do bairro", proveniente de sua descendência de antigos moradores de lugares específicos, que guardam idiossincrasias (p. 113).

As diversas experiências promovidas pela ocupação de espaços públicos, das rodas de samba e de sua execução nas escolas, permearam sociabilidades e arranjos espaciais que indicam resistências e segregações próprias do processo de formação urbana não só da cidade do Rio, mas também dos lugares em outras cidades, levando consigo alguns dos seus sentidos. De forma dinâmica, o samba e a experiência das conexões entre pessoas, tempos e espaços delimitaram lugares, marcaram e atravessaram fronteiras entre ruas, becos, bairros, "morro e asfalto", deslocaram-se, refiram-se em novos arranjos locais, nacionais, e transnacionais.

\section{Da Pequena África ao Brasil inteiro}

Com esse panorama apresentado, pretendo ainda avançar o debate sobre as apropriações de determinados lugares do samba, que são acionadas por meio de demandas contemporâneas específicas, como a de reconhecimento étnico e territorial. A exemplo dos processos de patrimonialização, ou de reivindicação de direitos, como no caso dos quilombos urbanos, o samba atua como um importante dispositivo que vincula as pessoas a lugares determinados.

Ainda como lugares ligados ao samba como espaços formalizados, aparecem os "quilombos urbanos". Guimarães (2011) problematiza o processo de implantação de projetos de "revitalização urbana" idealizados pela prefeitura carioca nos bairros portuários da Saúde, Gamboa e Santo Cristo. A autora analisa grupos que se posicionavam contrariamente às propostas e classificações da prefeitura, autoidentificando-se como herdeiros de um patrimônio "negro" e "do santo" e operando uma cosmologia e imaginário próprios, reiterando o "mito da Pequena África". Nesse contexto, o Quilombo da Pedra do Sal apresentou-se como um movimento de incorporação ao território, mais do que de exclusão dele. Como descreve a autora, há a intensificação de conflitos internos à própria Região Portuária, local que possui inúmeros imóveis vazios e abandonados e uma das maiores favelas da cidade, o Morro da Providência. Tais embates foram dinamizados pela possibilidade de uso de novas gramáticas políticas, baseadas na identificação de "memórias" e "práticas culturais tradicionais" do lugar.

A conexão entre sentimento e proximidade atualiza-se em contextos diversos de identificação com os lugares, como é o caso do Morro da Conceição, e da vinculação do samba a práticas antigas realizadas em tais localidades, propiciando assim a legitimação de sua ocupação. No processo acima descrito e analisado por Guimarães (2011), os espaços do Morro da Conceição e da Zona Portuária não eram apenas território e natureza inanimados a serem dominados e explorados economicamente, mas igualmente constituídos por humanos, animais, plantas, deuses e mortos, e em constante criação e dissolução.

Em 2005, um novo equipamento urbano, a "Cidade do Samba", foi construído pela Prefeitura no bairro da Gamboa, em um vasto terreno outrora pertencente à Rede Ferroviária Federal. Distribuídos ao redor de uma praça central, lá se encontram amplos galpões destinados à confecção das alegorias carnavalescas das escolas que desfilam no grupo especial. Para essas escolas, as condições outrora precárias de seus "barracões" foram substituídas por boas acomodações e por uma sofisticada infraestrutura. O interior desses novos galpões pode ser visualizado por visitantes e turistas. A administração da Cidade do Samba foi entregue pela Prefeitura à Liga Independente das Escolas de Samba, atestando a atuação do poder publico na legitimação da relação entre os lugares "tradicionais" do samba e as pessoas.

Outro exemplo etnográfico relacionado a uma nobre região da cidade do Rio de Janeiro é o caso da família Pinto, conhecida como família Sacopã, analisada por Mota (2012). A família, cuja moradia está localizada em um dos bairros mais nobres da cidade do Rio de Janeiro, a Lagoa Rodrigo de Freitas, formou-se a partir do patriarca, "Seu" Manoel Pinto, que chegou ao bairro nas primeiras décadas do século XX, com o propósito de trabalhar nas obras de abertura da Rua Sacopã. Era o início da "chegada da cidade" nessa área ainda quase desabitada, vindo a se tornar um dos bairros com o metro quadrado mais caro do Brasil. Mota (2012) indica que o samba do Sacopã, na década de 80 do século XX, figurou como um dos mais importantes redutos da manifestação da cultura carioca do samba na denominada zona sul da cidade do Rio de Janeiro. Era um reduto de "bambas" do samba, de admiradores desse estilo musical, de artistas, políticos, militantes do movimento negro, entre outros (p. 144-145).

Ressalto, desse caso, que o status de ser negro e o acionamento de diversos regimes como o samba se tornaram importantes instrumentos de visibilidade do grupo pela manutenção de seu lugar. Em determinado momento, no caso da família Sacopã (Mota, 2012), o samba, entre outros elementos, investiu o grupo de um status positivo para a afirmação de seu lugar no território, estabelecendo vinculações aproximadas às lutas políticas dos negros brasileiros, como símbolo maior pela conquista de seus direitos fundamentais. 


\section{De volta ao lugar - pertencimentos reivindicados}

Lugares como a Praça Onze, a região portuária, o Estácio, a Mangueira, a Madureira são frequentemente entoados nas letras de músicas, em manifestações culturais diversas, mesmo por aquelas pessoas que nunca foram moradoras de tais localidades ou que nunca lá estiveram. "Cantar a Mangueira”, "Eu sou Portela", "Ai, que saudades da Lapa" evocam imediatamente a relação com determinados lugares e expandem um território imaginado do samba carioca, compartilhado entre pessoas e grupos sociais por meio de redes sociais virtuais, com as inovações tecnológicas e recursos como a Internet.

Mas não apenas aí. A distância física, a descontinuidade territorial e a distância temporal não impedem a conexão entre pessoas e lugares. Por todo o território nacional, crescem as escolas de samba, os redutos do samba, os grupos de músicos. Osorio (2010), em seu estudo sobre a "Turma do Gambá" - grupo de músicos que tocava no "Botequim das quartas" em Brasília -, demonstra como uma ideia do Rio de Janeiro é ressemantizada no contexto da capital brasileira. Descreve a autora:

O Rio de Janeiro está nas músicas, nas poesias e nos sotaques. Os gambás não precisam se apresentar para a platéia como cariocas. Essa identificação se dá mesmo quando eles não dizem quem são, até porque muitos nem são realmente cariocas. $\mathrm{O}$ ambiente do Botequim é identificado por muitas pessoas como sendo um reduto carioca em Brasília. O jeito percebido como "descolado" e "malandro" garante esta identificação. E tal construção é edificada na performance dos gambás. (Osorio, 2010, p. 89)

Ferraz (2012, p. 226) realiza um estudo sobre uma rede de músicos autodidatas das cidades de São Paulo (SP), Porto Alegre (RS) e Uberlândia (MG), que mantêm relações entre si, intercambiando letras e gravações de músicos compositores cariocas e se encontram esporadicamente na realização de grandes "rodas de samba". No caso apresentado pela autora, os grupos de jovens se reúnem para a execução de referências musicais compartilhadas para comemorar, para lembrar-se das "brasas quentes" da Velha Guarda do samba. Tais processos, que expõem um aprendizado sensível, um modo de fazer, implicam o reconhecimento da riqueza cultural das produções do "morro”, uma produção que se afirma de classe e étnica.

\section{Considerações finais}

Diante da literatura apresentada sobre o samba, sugiro que a recorrência à evocação de determinados lugares, a exemplo do amplo território designado como "Pequena África", e das pessoas e compositores do samba "das antigas" promovem a presentificação de tais lugares nas ações contemporâneas. Movimentos sociais, redes de músicos que extravasam os limites do Rio de Janeiro são inspirados pela cidade. Não devem ser compreendidos como territórios fixos, essencializados, forma de interpretação criticada por Rodman (2003), mas, em outra direção, como um arranjo complexo que serve para falar sobre, lembrar e experimentar lugares ocupados ao longo de mais de um século na cidade do Rio de Janeiro, e que extrapola os seus limites temporais e espaciais. Tais espaços se fazem criativamente, a partir de um envolvimento mais amplo entre a intersubjetividade constitutiva das pessoas e os ambientes que experimentam e habitam (Ingold, 2002), tendo o samba e a "história" de suas pessoas e lugares como importantes referências.

As narrativas e experiências nesses lugares são movidas por inúmeras motivações, envolvendo religiosidade, cosmologias, patrimônio, entretenimento. Todas elas constituem instrumentos de estar no mundo e apreendê-lo de modo a relacionar determinadas categorias sociais e pessoas a territórios historicamente segregados, ou em disputa.

Assim, o lugar não evoca uma única maneira de experienciá-lo ou de compreendê-lo. Por isso, as imagens da Pequena África, por exemplo, parecem abrigar muitas vozes e perspectivas possíveis entre grupos e pessoas, ultrapassando os limites físicos e alcançando um potencial de reivindicações de direitos, como vimos com Guimarães (2012) e Oliveira et al. (2012).

Desse modo, a distância física ou temporal de lugares como a região da Pequena África, a Cidade Nova, o morro do Salgueiro ou da Mangueira, narrados por sua importância no passado, não necessariamente impede a construção de continuidades com as atuações e usos contemporâneos desse lugar. Ao contrário, os lugares e as pessoas são indissociáveis.

Com os distintos exemplos etnográficos, e reconhecendo a sua especificidade, busquei evidenciar que a experiência do samba nos lugares não é unívoca. Ao mencionar os lugares emblemáticos, não me pareceu que pudesse sintetizar uma única ou principal experiência promovida pelos seus usos. Afloram diversas construções em torno de pertencimentos que extravasam a limitação territorial ou temporal. Os lugares são tão parte das pessoas como as pessoas são parte de tais lugares (Basso, 1996).

O antropólogo José Reginaldo Gonçalves (2007, p. 214) problematiza as situações em que bens cultu- 
rais, classificados por uma agência de Estado como patrimônio, chegam ou não a encontrar reconhecimento de determinados setores da população. $\mathrm{O}$ antropólogo toca em um ponto sensível: "Um patrimônio não depende apenas da vontade e decisão políticas de uma agência de Estado. Nem depende exclusivamente de uma atividade consciente e deliberada de indivíduos ou grupos, mas precisam encontrar 'ressonância' junto a seu público" (Gonçalves, 2007, p. 215).

Vimos que alguns desses lugares, em diferentes planos de sentido, enfatizam a presença central de pessoas, como as mulheres "baianas" nas redes de sociabilidades que conformaram a cidade do Rio de Janeiro desde fins do século XIX. Sua presença reforça atividades sociais como a roda de samba, o ponto, a escola de samba, que constituem expressão cultural fundamentada pelas noções de apropriação coletiva do espaço público da cidade do Rio de Janeiro e de continuidade histórica, social e simbólica.

A antropóloga Nina Bitar (2011), em sua pesquisa sobre baianas de acarajé no Rio de Janeiro, chama a atenção para o evento do registro do "oficio das baianas de acarajé" realizado pelo Iphan em 2004 e que, além de ser um resultado de políticas públicas, foi gerado pelas baianas. A autora indica que, antes mesmo da ocorrência desse registro, a categoria patrimônio, de certa forma, já era produzida pelas baianas, embora estas não entendam a categoria do mesmo modo como os agentes do Iphan, nem circunscrevam sua compreensão a uma noção estritamente jurídica (Bitar, 2011, p. 201-202).

A visão sobre a presença das baianas em determinados lugares estratégicos na cidade, inclusive os dissensos e ambiguidades desse processo, são vitais para a eficácia dessa "referência cultural" e para a formulação de sua continuidade histórica, que atravessa contextos sociais diversos, como as baianas de acarajé ou as baianas em festa em um desfile de escola de samba, cuja coreografia remete às "matrizes" coreográficas do samba.

A vasta bibliografia a respeito do samba e dos baianos e baianas no Rio de Janeiro põe em destaque certa ideia de territorialidade, comensalidade, família, incluindo-se a forte referência à tia Ciata e à sua presença no samba e no carnaval. Como indica Arantes (2009), as culturas se recriam e se transformam historicamente, e os modos pelos quais as instituições, os valores e as atitudes se perpetuam ao longo do tempo não são simples mecanismos de transmissão de informação de uma geração a outra.

Sugiro, deste modo, que a ressonância produzida nos sujeitos pelos lugares do samba se faz a partir do "empoderamento" (Rodman, 2003) por eles engendrados. A imagem das baianas foi central nesse processo de empoderamento do lugar. Suas indumentárias, a comida e as atividades sociais centralizadas na figura feminina, negra, maternal, acolhedora e agregadora, constituem uma expressão cultural fundamentada pelas noções de apropriação coletiva do espaço público da cidade do Rio de Janeiro e de continuidade histórica, social e simbólica. Suas atuações como mediadoras fazem-se presentes nas alas das escolas de samba, nas quais muitas vezes são as responsáveis pela feijoada, pela articulação entre as pessoas. As diversas facetas que compõem o lugar social da "tia baiana", da "baiana do acarajé" ou da "baiana de escola de samba" são fundamentais para a eficácia de uma "concepção patrimonial da cultura" vigente na contemporaneidade.

No dossiê produzido pelo Centro Cultural Cartola e o Instituto do Patrimônio Histórico e Artístico Nacional, publicado em 2007, destacam-se alguns lugares recorrentes nas narrativas sobre o tema. Em um item especifico aos "lugares", há a seguinte descrição:

Desde o primeiro momento, nas décadas que abriram o século XX, o samba não se limitou a um lugar, a um espaço único de manifestação. Ainda que o terreiro da escola de samba (hoje, quadra) deva ser considerado um espaço privilegiado, fundamental para a sua criação e transmissão, o samba se deu e se dá em qualquer lugar, em qualquer hora, bastando que os sambistas se reúnam. Foi assim que ele se espalhou pela cidade, e é assim que ele ainda se manifesta hoje. (CCC/Iphan, 2007, p. 89)

Sugiro, por fim, que a ressonância produzida pelo samba na cidade do Rio de Janeiro se faz a partir de sua ampla capacidade de promover correlações entre pessoas e lugares, reciprocamente. Mais do que a soma de dados históricos ou de aspectos comuns a um território coletivo unívoco, o samba, os lugares e as pessoas, quando em relação, permitem desenhar múltiplos lugares sociais no espaço da cidade e para além dela, trazendo vozes e perspectivas à tona. Antes de estabelecer verdades absolutas, relacionam diferenças entre pessoas e lugares, tempos e espaços. 


\section{Referências}

ALVES, Diego Ramiro Araoz. Entregue o samba a seus donos: imagens e significados de Bahia no Rio de Janeiro da belle époque. Dissertação (Mestrado em Sociologia). Instituto de Ciências Sociais da Universidade Federal do Rio de Janeiro. Rio de Janeiro, 2006.

ARANTES, Antonio Augusto. Sobre inventários e outros instrumentos de salvaguarda do patrimônio cultural intangível: ensaio de antropologia pública. Anuário Antropológico, p. 173-222, 2009.

ARAÚJO, Eugênio. Não deixe o samba morrer: um estudo histórico e etnográfico sobre o carnaval de São Luís e a escola Favela do Samba. Dissertação. (Mestrado em História). Universidade Federal do Maranhão. São Luís, 2001.

BARBIERI, Ricardo José de Oliveira. Conflito e sociabilidade em uma pequena escola de samba: os Acadêmicos do Dendê da Ilha do Governador. Dissertação (Mestrado em Sociologia e Antropologia). Instituto de Filosofia e Ciências Sociais da Universidade Federal do Rio de Janeiro, Rio de Janeiro, 2010.

BARBIERI, Ricardo José de Oliveira. Cidade do samba: do barracão de escola às fábricas de carnaval. In: CAVALCANTI, Maria Laura; GONCALVES, Renata de Sá (Orgs). Carnaval em múltiplos planos. Rio de Janeiro: Aeroplano, 2009.

BARBOSA, Orestes. Samba: sua história, seus poetas, seus músicos e seus cantores. Rio de Janeiro: Funarte, 1978.

BASSO, Keith H. Wisdom sits in places: landscape and language among the Western Apache. Albuquerque: University of New Mexico Press, 1996.

BITAR, Nina Pinheiro. Baianas de acarajé: comida e patrimônio no Rio de Janeiro. Rio de Janeiro: Aeroplano, 2011.

BOAS, Franz. Geographical names of Kwakiutl indians. New York: Columbia University Constributions in Anthropology 20, 1934.

BLASS, Leila. Desfile na avenida, trabalho na escola de samba: a dupla face do carnaval. São Paulo: Annablume. 2007.

CARNEIRO, Ana. Quem roubou a "cultura”?: precisões conceituais e identificações não-identitárias de um "povo do samba". Revista de Antropologia, v. 52, n. 2, p. 677-704, jul./dez. 2009.

CARNEIRO, Edison. Desfiles e cortejos; Carta do Samba; Em louvor do rancho. Folguedos tradicionais. Rio de Janeiro: Funarte/INF, 1982.

CARNEIRO, Edison. Escolas de samba - I, Escolas de Samba - II. In: CARNEIRO, Edison. Sabedoria popular. São Paulo: Martins Fontes, 2008.

CASEY, Edward S. How to get from space to place in a fairly short stretch of time. In: FELD, Steven; BASSO, Keith (Orgs.) Senses of Place. Santa Fé, Novo México: School of American Research Press, 1996.

CAVAlCANTI, Maria Laura Viveiros de Castro. Carnaval Carioca: dos bastidores ao desfile. Rio de Janeiro: Ed. da UFRJ, 1994.
CCC/IPHAN - Centro Cultural Cartola/Instituto do Patrimônio Histórico e Artístico Nacional. Dossiê das matrizes do samba no Rio de Janeiro: partido alto, samba de terreiro e samba enredo, 2007.

DOZENA, Alessandro. As territorialidades do samba na cidade de São Paulo. Tese (Doutorado em Geografia). Faculdade de Filosofia, Letras e Ciências Humanas da Universidade de São Paulo. São Paulo, 2009.

DURKHEIM, Émile; MAUSS, Marcel. Algumas formas primitivas de classificação. Contribuição para o estudo das representações coletiva". In: MAUSS, Marcel. Ensaios de sociologia. São Paulo: Perspectiva, 1981.

EDMUNDO, Luís. O Rio de Janeiro do meu tempo. Rio de Janeiro: Conquista, 1957. 3v.

FERRAZ, Ana Lucia Camargo. A aprendizagem no samba: notas para o estudo de intensidades numa iniciação à etnomusicologia. Revista Ilha, v. 13(2), Florianópolis, 2012. FERREIRA, Felipe. Inventando carnavais: o surgimento do carnaval carioca no século XIX e outras questões carnavalescas. Rio de Janeiro: Ed. UFRJ, 2005.

GONÇALVES, José Reginaldo dos Santos. Antropologia dos objetos: coleções, museus e patrimônio. Rio de Janeiro: IPHAN/Departamento de Museus e Centros Culturais, 2007. p. 211-234.

GONCALVES, Renata de Sá. Cronistas, folcloristas e os ranchos carnavalescos: perspectivas sobre a cultura popular. Revista Estudos Históricos, n. 32, Rio de Janeiro, 2003.

GONCALVES, Renata de Sá. Os ranchos pedem passagem. O carnaval no Rio de Janeiro no começo do século XX. Rio de Janeiro: Coordenadoria de Documentação e Informação, Prefeitura do Rio de Janeiro, 2007.

GUIMARÃES, Roberta Sampaio. A utopia da Pequena África. Os espaços do patrimônio na Zona Portuária carioca. Tese (Doutorado em Sociologia e Antropologia). Instituto de Filosofia e Ciências Sociais da Universidade Federal do Rio de Janeiro. Rio de Janeiro, 2011.

GUIMARÃES, Roberta Sampaio. De monumento negro a território étnico: os usos do patrimônio cultural na produção de espaços urbanos diferenciados. In: TAMASO, Izabela Maria; LIMA FILHO, Manuel Ferreira. Antropologia e patrimônio cultural: trajetórias e conceitos. Brasília: Associação Brasileira de Antropologia, 2012.

GUTERRES, Liliane. "Sou Imperador até morrer". Um estudo sobre identidade, tempo e sociabilidade em uma escola de samba de Porto Alegre. Tese (Doutorado em Antropologia Social). Programa de Pós-graduação em Antropologia da Universidade Federal do Rio Grande do Sul. Porto Alegre, 1996.

HARVEY, David. Condição pós-moderna. São Paulo: Edições Loyola, 1992.

INGOLD, Tim. Building, dwelling, living: how animals and people make themselves at home in the world. In: INGOLD, Tim. The perception of the environment. Essays 
on Livelihood, Dwelling and Skill. Taylor \& Francis e-Library, 2002.

LEVI-STRAUSS, Claude. Antropologia estrutural. Rio de Janeiro: Tempo Brasileiro, 1975.

MENEZES, Hugo. Tem samba na terra do frevo! A batalha frevo x samba no carnaval multicultural do Recife. Textos escolhidos de cultura e arte populares. Rio de Janeiro, v. 7, n. 2, p. 45-59, nov. 2010.

MONTEIRO, Lucas. Carnaval capixaba: histórias, honras e glórias. Serra, ES: Ed. de Autor, 2010.

MOTA, Fabio Reis. Regimes de envolvimento e formas de reconhecimento no Brasil e na França. Revista Antropolítica (PPGA), Universidade Federal Fluminense, n. 1, 2012.

OLIVEIRA, Carmen Irene C. de et al. Pedra do Sal e Samba na Fonte: samba de raiz em um espaço fundados na perspectiva das paisagens culturais. In: TAMASO, Izabela Maria; LIMA FILHO, Manuel Ferreira. Antropologia e patrimônio cultural: trajetórias e conceitos. Brasília: Associação Brasileira de Antropologia, 2012.

OSORIO, Patrícia Silva. Música, performance e sociabilidade no botequim. In: TEIXEIRA, João Gabriel; VIANNA, Letícia (Orgs.). As artes populares no Planalto Central: performance e identidade. Brasília: Verbis Editora, 2010. POUBEL, Mayra Salgado. O bairro e a escola de samba: sociabilidade e pertencimento em Vila Isabel (RJ). Dissertação (Mestrado em Sociologia e Antropologia). Universidade Federal do Rio de Janeiro, Rio de Janeiro, 2012.
RODMAN, Margaret C. Empowering Place: multilocatity and multivocality. In: LOW, Setha; LAWRENCEZÚNIGA, Denise. The Anthropology of Space and Place: Locating Culture. Mas.: Blackwell Publishing, 2003.

SALES, Daniel. É tempo de sambar: história do carnaval de Manaus (com ênfase às escolas de samba). Manaus: Editora Nortemania, 2008.

SANDRONI, Carlos. Feitiço Decente: transformações do samba no Rio de Janeiro (1917-1933). Rio de Janeiro: Jorge Zahar/ Ed. UFRJ, 2001.

SIMSON, Olga. Carnaval em branco e negro: Carnaval popular paulistano 1914-1988. Campinas, SP: Editora da Unicamp, 2007.

TRAJANO FILHO, Wilson. Introdução. In: TRAJANO FILHO, Wilson (Org.) Lugares, pessoas e grupos: as lógicas do pertencimento em perspectiva internacional. Brasília: Athalaia Gráfica/ Editora Associação Brasileira de Antropologia, 2010.

VAGALUME. Na roda do samba. Rio de Janeiro: Funarte, 1978.

VELLOSO, Monica Pimenta. As tias baianas tomam conta do pedaço. Espaço e identidade cultural no Rio de Janeiro. Estudos Históricos. Rio de Janeiro, v. 3, n. 6, p. 207228, 1990.

VELloso, Monica Pimenta. A cultura das ruas no Rio de Janeiro (1900-1930): mediações, linguagens e espaço. Rio de Janeiro: Edições Casa de Rui Barbosa, 2004.

\title{
Yo soy la samba: sobre lugares, personas y pertenencia
}

\section{Resumen}

Este artículo se centra en el examen de ciertos "lugares" relacionados con la samba en la ciudad de Río de Janeiro, considerando aquellos percibidos como emblemáticos en la literatura sobre el tema. El objetivo es comprender las relaciones entre la samba, personas y lugares, con indicación de los distintos arreglos territoriales, morales y afectivos que engendran, sino también la presentificación de estos lugares en los movimientos sociales, eventos festivos y procesos patrimoniales.

Palabras clave: samba, el lugar, la pertenencia, Rio de Janeiro, el patrimonio cultural.

\section{I am the samba: concerning places, people and commitment}

\begin{abstract}
This article analyzes "places" that are associated with samba in the city of Rio de Janeiro considering the emblematic ones in the specialized studies. Our aim is to understand the relations between samba, people and places as territorial, cognitive, and moral arrangements, as well the presentification of these places in the social movements, festive events and heritage processes.
\end{abstract}

Key words: samba, place, commitment, Rio de Janeiro, cultural heritage.

Data de recebimento do artigo: 30/01/ 2013

Data de aprovação do artigo: 16/05/2013 